\title{
KETERKAITAN JALINAN INTERPERSONAL DAN TEMPAT KERJA TERHADAP KEPUASAN KERJA KARYAWAN MA'HAD MUHAMMADIYAH DAARUL ULUM MAJENANG CILACAP
}

\author{
Mudiono $^{1}$ \\ Ali Sya'bana ${ }^{2}$ \\ Syarmilah $\mathrm{Umar}^{3}$ \\ Aftoni Sutanto ${ }^{4}$ \\ Salamatun Asakdiyah ${ }^{5}$ \\ 1,2,3,4,5 Universitas Ahmad Dahlan Yogyakarta \\ mudionopjk@gmail.com
}

\begin{abstract}
This paper tries to reveal the relationship of interpersonal relation and work environment toward job satisfaction of employees in ma'had Muhammadiyah Daarul Ulum Majenang Cilacap. This research was carried out on all existing active employee, which are 50 people. This study utilizes the instrument test and hypothesis test through SPSS 16.0 for Windows. The findings show that based on the t test, the value of $t_{\text {count }}$ is $3.147>t_{\text {table }} 1.299$ and the significant value is $0.003<0.05$. Therefore, it can be claimed that partially interpersonal relations (X1) significantly influence employee job satisfaction. While the work environment variable $t_{\text {count }} 10.390>t_{\text {table }} 1.299$ and a significant value of $0.000<0.05$. Consequently, it can be claimed that partially work environment consist of a substantial influence on employee job satisfaction. Based on the $F$ test, $F_{\text {count }} 194.06>F_{\text {table }} 3.19$. Hence, it proved that interpersonal relations and work environment jointly influence job contentment. Furthermore, the analysis of determination shows a significant contribution from interpersonal relations and work environment on employee job contentment, as obtained $R$ square (R2) of 0.892. Thus, $89.2 \%$ of employee job satisfaction is influenced by interpersonal relations and work environment, while the remaining $10.8 \%$ is affected by different variables which is not executed in this study.
\end{abstract}

Keywords: interpersonal relationships, work environment and job satisfaction.

\section{PENDAHULUAN}

\section{Latar Belakang}

Perkembangan dunia asrama atau yang biasa disebut mahad dari waktu ke waktu semakin dinamis, sehingga menuntut manajemen mampu berkompetisi dengan mahad yang lain. Sumber daya manusia disebut sebagai salah satu penggerak utama kegiatan manajemen. Beberapa faktor perlu diperhatikan oleh manajemen: jalinan antar individu, tempat kerja dan kepuasan kerja. Pada bagian pertama, individu harus memiliki jalinan dengan individu lain agar mampu bersinergi dengan baik. Jalinan tersebut, jika terpola dengan baik dapat menjadi elemen penentu kelancaran seseorang dalam bekerja. Yang kedua, lingkungan kerja patut diperhatikan dalam sebuah manajemen. Walaupun lingkungan kerja tidak terlibat dalam proses produksi yang terjadi pada suatu manajemen, namun memiliki keterkaitan langsung 
dengan kegiatan produksi tersebut. Jika suasana tempat kerja terkendali dan nyaman maka karyawan akan bekerja dengan senang hati. Yang ketiga, karyawan memiliki kepuasan dalam proses kerja akan berusaha semaksimal mungkin untuk bertanggungjawab menyelesaikan tugas dan pekerjaannya. Ma'had Muhammadiyah Daarul Ulum Majenang Cilacap adalah sebuah perguruan yang beralamat di jalan Sirkaya no. 10 Majenang Cilacap. Berdiri sejak tahun 1990 dengan sk Wk/5a/PP.03.2/34/90. Aktifitas usaha yang dilakukan lembaga ini adalah sekolah berasrama dari tingkat dasar, tsanawiyah dan aliyah. Santri berasal dari berbagai propinsi dan kota di sekitarnya.

Temuan awal peneliti yaitu adanya hubungan interpersonal yang sudah baik, hal ini terlihat pada adanya rasa empati, saling mendukung dan saling terbuka dengan rekan kerja lainnya. Keharmonisan dalam bekerja menimbulkan kondisi kerja yang menyenangkan dan kenyamanan kerja. Hal ini sangat penting untuk terus dikembangkan agar tidak menganggu hubungan interpersonal karyawan.

Lingkungan kerja di Ma'had Daarul Ulum Muhammadiyah Majenang sangat terkendali, hal ini dapat dilihat dari lokasi tempat kerja yang berdekatan pusat kota, sisi pencahayaan walaupun menggunakan lampu listrik, tapi pengaturan lampunya sudah bagus untuk menerangi ruang kerja. Demikian juga sisi ruangan kerja dan kelas yang masih sederhana namun masih bisa dimanfaatkan secara maksimal. Walaupun hubungan interpersonal dan lingkungan kerja dalam kondisi yang baik namun pada sisi kepuasan kerja karyawan yang ada pada Ma'had Daarul Ulum Muhammaadiyah Majenang terlihat masih kurang. Hal ini terlihat masih adanya beberapa ketidak hadiran karyawan pada setiap bulannya. Sehingga pengkajian ini dilaksanakan untuk mengidentifikasi keterkaitan antara hubungan interpersonal, pengaruh Lingkungan kerja. Selanjutnya, digunakan untuk menguji adanya keterkaitan secara berurutan antara jalinan antar individu dan tempat kerja dan kepuasan kerja karyawan.

\section{TINJAUAN PUSTAKA}

Pakar mengatakan bahwa,
"Hubungan interpersonal adalah
hubungan yang terdiri dari dua orang
atau lebih yang saling tergantung satu
sama lain dan menggunakan pola
interaksi yang konsisten"
(Wisnuwardhani dan Mashoedi:2012).
Di sisi lain, hal tersebut adalah
hubungan antar manusia yang selaras,
dengan sengaja dan bersedia saling
mengalah demi tergapainya kepentingan
bersama (Hasibuan:2009). Selanjutnya,


pendapat Robbins (2007), "Hubungan interpersonal adalah interaksi antara seseorang dengan orang lain dalam situasi kerja dan dalam organisasi sebagai motivasi untuk bekerjasama secara produktif. Sehingga dicapai kepuasan ekonomi, psikologis dan sosial". Sehingga, dapat dinyatakan bahwa hubungan interpersonal memiliki kaitan yang penting dalam pekerjaan yang dilakukan oleh beberapa orang dalam suatu lingkungan kerja.

Menurut Sutalaksana (2006: 90), "Lingkungan kerja adalah segala sesuatu yang ada disekitar para karyawan dan yang dapat memengaruhi karyawan tersebut dalam menjalankan tugas-tugas yang dibebankan". Menurut Rivai (2006), “Lingkungan kerja adalah keseluruhan sarana dan prasarana yang ada disekitar karyawan yang sedang melakukan pekerjaan itu sendiri." Faktor yang memiliki dampak pada lingkungan kerja sesuai pendapat Wane P. dan Schultz dalam Mangkunegara (2005: 105), mengungkapkan faktor-faktor lingkungan kerja yang dapat memengaruhi karyawan dalam bekerja, yang juga merupakan dimensi dari lingkungan kerja adalah: pertama kondisi fisik yang meliputi penerangan (cahaya), cahaya lampu yang tidak memadai berpengaruh negatif terhadap keterampilan kerja.

"Kepuasan kerja (job satisfaction) adalah keadaan emosional yang menyenangkan atau tidak menyenangkan dengan cara para karyawan memandang pekerjaan mereka" (Handoko:2008). Pernyataan tersebut ditunjukkan pada sikap karyawan yang selalu baik terhadap apapun yang ada di tempat kerja. Hasibuan (2009), menyatakan bahwa "Karyawan yang lebih suka menikmati kepuasan kerja dalam pekerjaan akan lebih mengutamakan pekerjaannya daripada balas jasa walaupun balas jasa itu penting". Menurut Robins (2007: 36), berpendapat bahwa : "Kepuasan kerja (job satisfaction) adalah sikap umum individu terhadap pekerjannya. Seseorang dengan tingkat kepuasan kerja yang tinggi mempunyai sikap positif terhadap pekerjaannya, sesorang yang tidak puas dengan pekerjaannya mempunyai sikap negatif terhadap pekerjaan tersebut".

Faktor-faktor yang berkaitan dengan kepuasan kerja menurut Siagian (2008: 295), antara lain faktor psikologis, meliputi ketentraman dalam bekerja, minat, bakat dan keterampilan. Faktor kedua merupakan faktor sosial, meliputi hubungan dengan rekan kerja dan hubungan atasan dengan karyawan. Selain itu, terdapat faktor fisik/ lingkungan, yang berhubungan dengan waktu istirahat, perlengkapan pekerjaan dan keadaan ruangan. 


\section{FAKULTAS EKONOMI DAN BISNIS UNIVERSITAS WIRARAJA - SUMENEP}

\section{Hipotesis}

Berdasarkan latar belakang diatas, maka dapat diputuskan beberapa hipotesa sebagai berikut:

H1: Adanya keterkaitan yang kuat antara hubungan antar individu dengan kepuasan kerja karyawan.

H2: Adanya keterkaitan yang kuat antara tempat kerja dengan kepuasan kerja karyawan.

H3: Adanya pengaruh yang kuat secara berkesinambungan antara jalinan antar individu dan tempat kerja terhadap kenyamanan kerja karyawan.

\section{Kerangka Penelitian}

Dapat dijelaskan bahwa membina hubungan interpersonal secara ideal dapat tercipta kerjasama yang solid di manajemen. Lingkungan kerja yang baik juga dapat merangsang karyawan untuk lebih semangat dalam bekerja dan menghasilkan apa yang menjadi tujuan manajemen yaitu produktivitas yang meningkat. Untuk itu perlu diperhatikan hubungan interpersonal dengan lingkungan kerja yang mendorong pelaksanaan kerja karyawan. Dari penjelasan diatas, penulis dapat memberikan suatu gambaran kerangka pemikiran yang singkat, yaitu dapat dilihat dalam bagan dibawah

ini:

Gambar 1

\section{Konsep Penelitian}

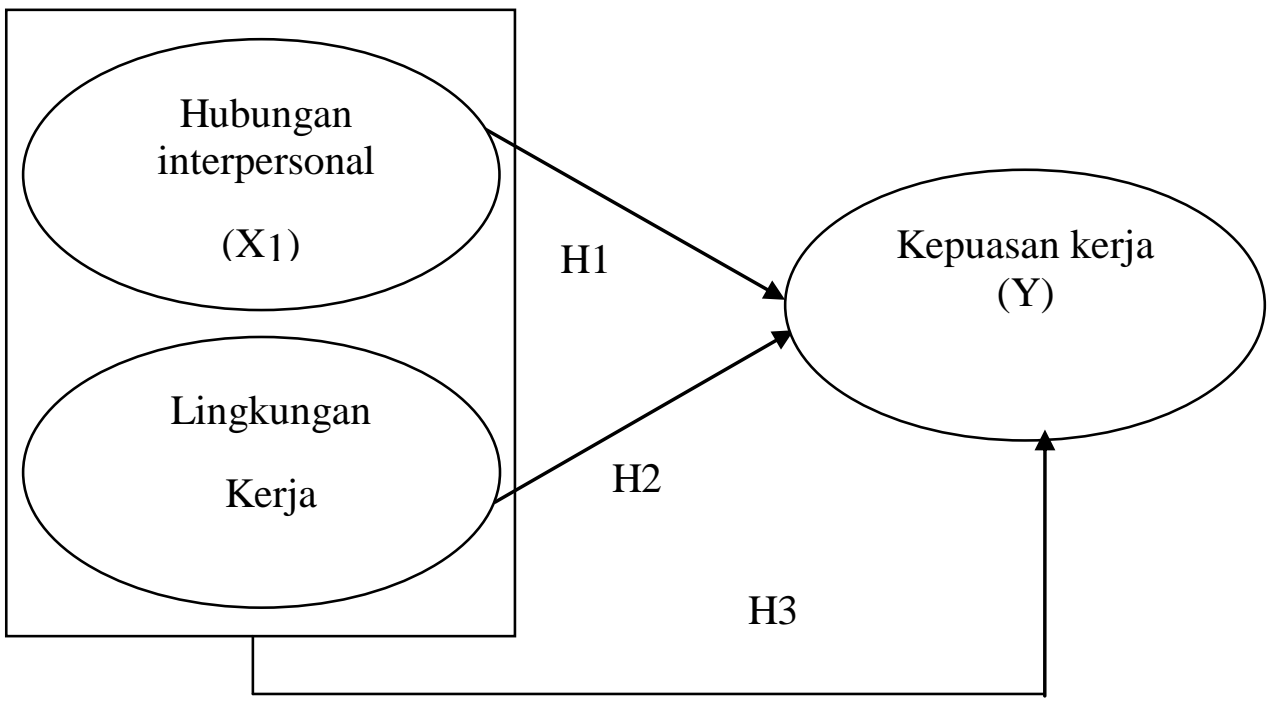

Keterangan :

Variabel $\mathrm{X}_{1}$ berpengaruh terhadap y

Variabel $\mathrm{X}_{2}$ berpengaruh terhadap y

Variabel X1, dan Variabel X2 secara simultan memiliki keterkaitan dengan y 
METODE PENELITIAN

Pengujian ini merupakan bentuk dari penelitian diskriptif kuantitatif dan pengumpulan data menggunakan purposive sampling technique. Data dianalisa menggunakan metode analisa deskriptif dan verifikatif. Sumber data penelitian adalah karyawan yang berada dalam lingkungan Ma'had Muhammadiyah Daarul Ulum yang beralamat di jalan Sirkaya No.10 Majenang Cilacap. Dan jumlah karyawan yang ada sejumlah 50 orang. Selanjutnya, populasi menurut Suharsimi Arikunto (1996: 106)
"Populasi adalah sekelompok orang, kejadian, atau segala sesuatu yang mempunyai karakteristik tertentu". Data yang diproses dalam pengujian ini diperoleh dari kuesioner untuk karyawan Ma'had Daarul Ulum Muhammadiyah Majenang Cilacap. Populasi pada studi ini adalah semua karyawan Ma'had Muhammadiyah Daarul Ulum Majenang Cilacap sebanyak 50 orang. Sedangkan Instrumen yang digunakan dalam pengujian ini berupa angket yang dibuat sesuai dengan poin sebagai berikut:

Tabel 1

Poin-poin Instrumen Penelitian

\begin{tabular}{|c|c|c|}
\hline Konstruk & Indikator Variabel & Poin \\
\hline \multirow{3}{*}{$\begin{array}{l}\text { Hubungan } \\
\text { interpersonal }\end{array}$} & Sikap percaya & Acceptance, empathy dan trust \\
\hline & Sikap adil & $\begin{array}{l}\text { Profesionalisme, deskripsi, orientasi masalah, } \\
\text { spontanitas, dan persamaan }\end{array}$ \\
\hline & Sikap terbuka & $\begin{array}{l}\text { membandingkan pesan dengan objektif, fokus pada } \\
\text { inti komunikasi, menggali informasi dan makna } \\
\text { komunikasi yang berbeda dengan urutan } \\
\text { kebenarannva }\end{array}$ \\
\hline \multirow{3}{*}{$\begin{array}{l}\text { Lingkungan } \\
\text { kerja }\end{array}$} & Kondisi fisik & Penerangan (cahaya), warna, suhu, dan suara. \\
\hline & Kondisi psikis & Perasaan bosan dan perasaan letih \\
\hline & Kondisi temporer & Jumlah iam keria dan waktu istirahat keria \\
\hline \multirow{3}{*}{ Kepuasan kerja } & Moral kerja & $\begin{array}{l}\text { Rasa memiliki terhadap pekerjaan dan tanggung } \\
\text { jawab terhadap pekerjaan }\end{array}$ \\
\hline & Kedisiplinan & Ketepatan waktu bekerja dan ketepatan metode kerja \\
\hline & $\overline{P r e}$ & $\begin{array}{l}\text { Output/hasil kerja yang optimal dan Out } \\
\text { kerja yang memenuhi standar }\end{array}$ \\
\hline
\end{tabular}

Sumber: Rakhmat, (2011), Mangkunegara (2005), Hasibuan (2008)

Dalam penelitian ini digunakan 5 skala Likert dengan urutan sebagai berikut: 
Tabel 2.

Urutan Skala Likert

\begin{tabular}{ccccc}
\hline sangat tidak setuju & tidak setuju & netral & setuju & sangat setuju \\
\hline 1 & 2 & 3 & 4 & 5 \\
\hline
\end{tabular}

Sumber: Sekaran (2006)

diolah melalui beberapa pengujian meliputi : t-test, analisis regresi

Analisa data dilakukan berganda, F-test, dan koefisien menggunakan analisa data kuantitatif, yaitu dengan cara menyusun data, menggelompokkannya, dan menjelaskan maknanya sehingga diperoleh hasil yang valid terkait dengan masalah yang diuji. Untuk mengambil kesimpulan dan seberapa pengaruh variabel independentt terhadap dependent, yang sebelumnya dilakukan pengujian instrumen penelitian melalui beberapa tahapan meliputi uji reliabilitas dan validitas. Sedangkan hasil dari instrumen tersebut determinasi $\left(\mathrm{R}^{2}\right)$

\section{HASIL PENELITIAN DAN}

\section{PEMBAHASAN}

\section{Analisis Deskripsi Variabel Penelitian}

Tanggapan responden terhadap

\section{hubungan interpersonal}

Pembahasan deskriptif tentang Hubungan interpersonal berdasarkan tiga dimensi yaitu sikap percaya, sikap suportif, sikap terbuka dengan duabelas pertanyaan. Hasil rekapitulasi jawaban responden adalah sebagai berikut:

Tabel 3

Rekapitulasi Jumlah Skor Jawaban Responden Variabel Hubungan interpersonal

\begin{tabular}{ccc}
\hline No. Urut & Nomor Pertanyaan & Jumlah Skor \\
\hline 1 & 1 & 229 \\
\hline 2 & 2 & 227 \\
\hline 3 & 3 & 216 \\
\hline 4 & 4 & 222 \\
\hline 5 & 5 & 227 \\
\hline 6 & 6 & 227 \\
\hline 7 & 7 & 225 \\
\hline 8 & 8 & 211 \\
\hline 9 & 9 & 229 \\
\hline 10 & 10 & 223 \\
\hline 11 & 11 & 213 \\
\hline 12 & 12 & 225 \\
\hline & Jumlah Skor Total & 2674
\end{tabular}

Sumber: Hasil penelitian diolah (2019)

Selanjunya dari nilai sekor yang diperoleh penulis melakukan pengkategorian sebagai berikut:

Nilai Indeks Minimum $=$ Bobot minimum $\times$ jumlah pertan $y a a n \times$ jumlah responden $=1$ $\times 12 \times 50=600$

Nilai Indeks Maksimum $=$ Bobot maksimum $\times$ jumlah pertanyaan $\times$ jumlah responden $=$ $5 \times 12 \times 50=3.000$ 


Interval $=\quad \frac{\text { Nilai Indeks Maksimum }- \text { Nilai Indeks Minimum }}{\text { Jumlah Kategori }}$
$=$
$=480$

Berdasarkan perhitungan di atas, interpersonal di Ma'had untuk menunjukkan kelompok sesuai Muhammadiyah Daarul Ulum kategori sesuai Tabel 2. disajikan Majenang Cilacap termasuk kategori interval sebagaimana tabel 4 .

Dari data kuesioner, tanggapan Sangat Baik.

Tanggapan responden terhadap karyawan Ma'had Muhammadiyah Daarul Ulum Majenang Cilacap terhadap variabel Hubungan interpersonal diperoleh skor total untuk seluruh item pertanyaan sebesar 2674, hal ini menunjukkan bahwa hasil penelitian terhadap Hubungan

\section{lingkungan kerja}

Lingkungan kerja diukur oleh tiga dimensi yaitu kondisi fisik, kondisi psikis dan kondisi temporer dengan sepuluh pertanyaan. Hasil rekapitulasi jawaban responden adalah sebagaimana tabel 5:

Tabel 4

Interval rekapitulasi variabel hubungan interpersonal

\begin{tabular}{ccc}
\hline No. & Kriteria Penilaian & Interval \\
\hline 1 & Sangat tidak Setuju & $600-1080$ \\
\hline 2 & Tidak setuju & $1081-1560$ \\
\hline 3 & Netral & $1561-2040$ \\
\hline 4 & Setuju & $2041-2520$ \\
\hline 5 & Sangat setuju & $2521-3000$ \\
\hline
\end{tabular}

Sumber: Hasil penelitian diolah (2019)

Tabel 5

Rekapitulasi jumlah skor jawaban responden variabel lingkungan kerja

\begin{tabular}{ccc}
\hline No. Urut & Nomor Pertanyaan & Jumlah Skor \\
\hline 1 & 1 & 206 \\
\hline 2 & 2 & 214 \\
\hline 3 & 3 & 213 \\
\hline 4 & 4 & 194 \\
\hline 5 & 5 & 213 \\
\hline 6 & 6 & 209 \\
\hline 7 & 7 & 219 \\
\hline 8 & 8 & 223 \\
\hline 9 & 9 & 215 \\
\hline 10 & 10 & 215 \\
\hline & Jumlah Skor Total \\
\hline
\end{tabular}

Sumber: Hasil penelitian diolah (2019) 
Dengan metode pengkategorian yang sama seperti diatas, maka dihasilkan interval sebagaimana tabel 6.

Dari data kuesioner, tanggapan karyawan Ma'had Muhammadiyah Daarul Ulum Majenang Cilacap terhadap variabel Lingkungan kerja, diperoleh skor total untuk seluruh item pertanyaan sebesar 2121, hal ini menunjukkan bahwa hasil penelitian terhadap Lingkungan kerja di Ma'had Muhammadiyah Daarul Ulum
Majenang Cilacap termasuk kategori Sangat Baik

Tanggapan responden terhadap kepuasan kerja karyawan

Kepuasan kerja karyawan dapat diukur dengan tiga dimensi yaitu; moral kerja, kedisiplinan dan prestasi kerja dengan empat belas pertanyaan. Hasil rekapitulasi jawaban responden terhadap pertanyaan yang menjelaskan tentang kepuasan kerja karyawan, yaitu seperti

tabel

\section{Tabel 6}

Interval rekapitulasi variabel lingkungan kerja

\begin{tabular}{ccc}
\hline No. & Kriteria Penilaian & Interval \\
\hline 1 & sangat tidak Setuju & $500-900$ \\
\hline 2 & tidak setuju & $901-1300$ \\
\hline 3 & netral & $1301-1700$ \\
\hline 4 & setuju & $1701-2100$ \\
\hline 5 & Sangat setuju & $2101-2500$ \\
\hline
\end{tabular}

Sumber: Hasil penelitian diolah (2019)

Tabel 7

Rekapitulasi jumlah skor jawaban responden variabel kepuasan kerja karyawan

\begin{tabular}{ccc}
\hline No. Urut & Nomor Pertanyaan & Jumlah Skor \\
\hline 1 & 1 & 224 \\
\hline 2 & 2 & 218 \\
\hline 3 & 3 & 206 \\
\hline 4 & 4 & 222 \\
\hline 5 & 5 & 221 \\
\hline 6 & 6 & 217 \\
\hline 7 & 7 & 205 \\
\hline 8 & 8 & 223 \\
\hline 9 & 9 & 220 \\
\hline 10 & 10 & 225 \\
\hline 11 & 11 & 213 \\
\hline 12 & 12 & 210 \\
\hline 13 & 13 & 208 \\
\hline 14 & 14 & 220 \\
\hline & Jumlah Skor Total & 3032 \\
\hline
\end{tabular}

Sumber: Hasil penelitian diolah (2019) 
Dengan metode pengkategorian yang sama seperti diatas, maka dihasilkan interval sebagaimana tabel 8 .

Tabel 8

Interval Rekapitulasi Variabel Kepuasan Kerja Karyawan

\begin{tabular}{lcc}
\hline No. & Kriteria Penilaian & Interval \\
\hline 1 & sangat tidak Setuju & $700-1260$ \\
\hline 2 & tidak setuju & $1261-1820$ \\
\hline 3 & netral & $1821-2380$ \\
\hline 4 & setuju & $2381-2940$ \\
\hline 5 & sangat setuju & $2941-3500$ \\
\hline
\end{tabular}

Sumber: Hasil penelitian diolah (2019)

Dari data kuesioner, tanggapan karyawan Ma'had Muhammadiyah Daarul Ulum Majenang Cilacap terhadap variabel Kepuasan kerja karyawan diperoleh skor total untuk seluruh item pertanyaan sebesar 3032, hal ini menunjukkan bahwa hasil penelitian terhadap Kepuasan kerja karyawan di Ma'had Muhammadiyah Daarul Ulum Majenang Cilacap termasuk kategori Sangat Baik.

\section{Uji Hipotesis Penelitian}

\section{Analisis regresi berganda}

Untuk mendapatkan besarnya keterkaitan antara jalinan interpersonal dan tempat kerja pada kepuasan kerja karyawan Ma'had Muhammadiyah Daarul Ulum Majenang, maka digunakan metode regresi linier berganda sebagai suatu alat ukur.

\section{Tabel 9}

Multiple Regression

\section{Coefficients $^{\mathrm{a}}$}

\begin{tabular}{ccccccc}
\hline \multirow{2}{*}{ Model } & \multicolumn{2}{c}{$\begin{array}{c}\text { Unstandardized } \\
\text { Coefficients }\end{array}$} & \multicolumn{2}{c}{$\begin{array}{c}\text { Standardized } \\
\text { Coefficients }\end{array}$} & & \\
\cline { 2 - 5 } & & B & Std. Error & Beta & T & Sig. \\
\hline 1 & (Constant) & 2.900 & 4.118 & & .704 & .485 \\
\cline { 2 - 5 } & .359 & .114 & .230 & 3.147 & .003 \\
\hline HI & .35 & .087 & .759 & 10.390 & .000 \\
\hline
\end{tabular}

a. Variabel Terikat: KP

Sumber: SPSS 16.0 
Tabel diatas menunjukkan bahwa acuan regresi linier berganda sebagai berikut $\mathrm{Y}=2.900+0.359 \mathrm{X}_{1}+0.908 \mathrm{X}_{2}$. Nilai diatas dapat dijabarkan dengan cara sebagai berikut: Nilai tetap sebesar 2,900 bermakna jika hubungan interpersonal dan lingkungan kerja nilainya diasumsikan nol (0), maka nilai dari kepuasan kerja adalah 2,900. Koefisien regresi sebesar 0,359 bermakna apabila hubungan interpersonal naik maka, maka kepuasan kerja akan naik 0,359. Koefisien regresi menunjukkan angka 0,908 yang bermakna jika lingkungan kerja semakin baik, maka kepuasan kerja akan naik 0,908

\section{Uji signifikan parsial (Uji T)}

$\mathrm{H} 1=$ Terdapat keterkaitan yang kuat antara hubungan interpersonal pada kepuasan kerja karyawan.

$\mathrm{H} 2=$ Terdapat keterkaitan yang kuat antara lingkungan kerja pada kepuasan kerja karyawan.

Variabel jalinan antar individu menunjukkan bahwa secara parsial hubungan interpersonal (X1) memiliki pengaruh yang kuat terhadap kepuasan kerja karyawan. Pada variabel lingkungan kerja, nilai thitung menunjukkan $10.390>$ ttabel 1,299 (sig. $0,000<0,05)$. Sehingga dapat dipastikan bahwa secara parsial lingkungan kerja memiliki dampak yang kuat terhadap kepuasan kerja karyawan.

\section{Uji signifikan simultan (Uji F)}

F-test diberlakukan untuk menunjukkan bahwa jalinan antar individu dan lingkungan kerja memilliki keterkaitan bersamaan dengan kepuasan kerja.

Berdasarkan hasil pada tabel, nilai $F_{\text {hitung }} 194.06>F_{\text {tabel }} 3,19$, sehingga dapat dinyatakan bahwa jalinan antar individu dan tempat kerja secara berkesinambungan memiliki pengaruh terhadap kepuasan kerja. Dengan probabilitas (sig. 0,000<0.05), maka dapat disimpulkan bahwa model persamaan tersebut memiliki pengaruh.

\section{Koefisien determinasi}

Untuk membuktikan dampak dari hubungan interpersonal (XI) terhadap kepuasan kerja karyawan (Y), lingkungan kerja $\left(\mathrm{X}_{2}\right) \quad$ terhadap kepuasan kerja karyawan (Y), maka digunakan koefisien determinasi.

Dapat dilihat bahwa $\mathrm{R}$ sebesar 0,994 dan R square (R2) adalah 0,892. Berarti 89,2\% Kepuasan kerja karyawan dapat dijelaskan oleh jalinan antar individu dan lingkungan kerja, sedangkan sisanya $10,8 \%$ dijelaskan oleh faktor lain yang tidak dikaji dalam pengujian ini. 
Tabel 10

Signifikan Parsial (Uji T)

Coefficients $^{\text {a }}$

\begin{tabular}{ccccccc}
\hline \multirow{2}{*}{ Model } & \multicolumn{2}{c}{$\begin{array}{c}\text { Unstandardized } \\
\text { Coefficients }\end{array}$} & \multicolumn{2}{c}{$\begin{array}{c}\text { Standardized } \\
\text { Coefficients }\end{array}$} & & \\
\cline { 3 - 5 } & & $\mathrm{B}$ & Std. Error & Beta & & Sig. \\
\hline 1 & (Constant) & 2.900 & 4.118 & & .704 & .485 \\
\cline { 2 - 5 } & HI & .359 & .114 & .230 & 3.147 & .003 \\
\hline & LK & .908 & .087 & .759 & 10.390 & .000 \\
\hline
\end{tabular}

a. Variable Terikat: KP

Sumber: SPSS 16.0 (2019)

Tabel 11

Signifikan Simultan (Uji F)

\begin{tabular}{cccccc}
\multicolumn{8}{c}{ ANOVA $^{\mathbf{b}}$} & & & \\
\hline Model & Sum of Squares & Df & Mean Square & F & Sig. \\
\hline Regression & 1353.607 & 2 & 676.803 & 194.065 & $.000^{\mathbf{a}}$ \\
\hline Residual & 163.913 & 47 & 3.488 & & \\
\hline Total & 1517.520 & 49 & & & \\
\hline
\end{tabular}

a. Predictors: (Constant), LK, HI

b. Dependent Variable: KP

Sumber: Hasil olahan SPSS 16.0 (2019)

Tabel 12

Koefisien Determinasi

Model Summary ${ }^{\mathrm{b}}$

\begin{tabular}{cccccc}
\hline Model & $\mathrm{R}$ & R Square & Adjusted R & Std. Error of & Durbin-Watson \\
\hline 1 & $.944^{\mathrm{a}}$ & .892 & .887 & 1.86749 & 2.306 \\
\hline
\end{tabular}

a. Predictors: (Constant), LK, HI

b. Dependent Variable: KP

Sumber: Hasil olahan SPSS 16.0 (2019)

PEMBAHASAN

Hubungan interpersonal pada ma'had muhammadiyah daarul ulum majenang cilacap.

Hubungan interpersonal Ma'had Muhammadiyah Daarul Ulum Majenang Cilacap berdasarkan tanggapan responden diperoleh skor total untuk seluruh item pertanyaan sebesar 2674, hal ini menunjukkan bahwa hasil penelitian terhadap hubungan interpersonal dalam kategori sangat baik.

Total skor item tertinggi hubungan interpersonal dapat dilihat pada item nomor 1 yang menyatakan karyawan sangat menghargai perbedaan latar belakang diantara rekan kerja dan

PERFORMANCE : Jurnal Bisnis \& Akuntansi Volume 9, No.2,September 2019 
menerima perbedaan. Meskipun

Hubungan interpersonal sudah sangat baik namun masih adanya kendala yang dihadapi yaitu dapat dilihat dari item terendah yaitu nomor 8 yang menyatakan tentang menjalankan tugas dengan penuh rasa tanggungjawab.

$\begin{array}{ccr}\begin{array}{l}\text { Lingkungan kerja } \\ \text { muhammadiyah }\end{array} & \text { daarul } & \begin{array}{r}\text { ma'had } \\ \text { ulum }\end{array} \\ \text { majenang cilacap } & & \\ \text { Lingkungan } & \text { kerja } & \text { Ma'had } \\ \text { Muhammadiyah } & \text { Daarul } & \text { Ulum }\end{array}$

Majenang Cilacap berdasarkan tanggapan responden diperoleh skor total untuk seluruh item pertanyaan sebesar 2121, hal ini menunjukkan bahwa hasil penelitian terhadap lingkungan kerja termasuk kategori sangat baik. Total skor item tertinggi pada lingkungan kerja dapat dilihat pada item nomor 8 yang menyatakan karyawan dapat bekerja dengan senang dengan kondisi lingkungan yang ada. Meskipun lingkungan kerja sudah sangat baik namun masih adanya kendala yang dihadapi yaitu dapat dilihat dari item terendah yaitu item nomor 1 yang menyatakan penerangan di ruang kerja kurang dapat memperlancar proses kerja.

Kepuasan kerja karyawan pada ma'had muhammadiyah daarul ulum majenang cilacap

Kepuasan kerja karyawan Ma'had Muhammadiyah Daarul Ulum
Majenang Cilacap berdasarkan tanggapan responden diperoleh skor total untuk seluruh item pertanyaan sebesar 3032, hal ini menunjukkan bahwa hasil penelitian terhadap kepuasan kerja karyawan termasuk kategori sangat baik. Total skor item tertinggi pada kepuasan kerja karyawan dapat dilihat pada item nomor 10 yang menyatakan karyawan selalu berusaha untuk tidak suka menunda-nunda pekerjaan yang telah ditetapkan. Meskipun kepuasan kerja karyawan sudah sangat baik namun masih kurang maksimal, hal tersebut dikarenakan masih adanya kendala yang dihadapi yaitu dapat dilihat dari item terendah nomor 7 yang menyatakan sebagian melakukan semua pekerjaan sesuai dengan ketentuan dan cara kerja.

Keterkaitan hubungan interpersonal terhadap kepuasan kerja karyawan pada ma'had muhammadiyah daarul ulum majenang cilacap

Hasil hitung dari persamaan regresi linier berganda diperoleh nilai hubungan interpersonal dengan koefisien regresi sebesar 0,359 . Hal ini bermakna bahwa semakin tinggi hubungan interpersonal, maka semakin tinggi kepuasan kerja. Hal ini menunjukkan bahwa terdapat pengaruh yang kuat antara hubungan interpersonal terhadap kepuasan kerja karyawan. 


\section{FAKULTAS EKONOMI DAN BISNIS UNIVERSITAS WIRARAJA - SUMENEP}

Pengaruh lingkungan kerja terhadap kepuasan kerja karyawan pada ma'had muhammadiyah daarul ulum majenang cilacap

Hasil hitung dari persamaan regresi linier berganda diperoleh variabel lingkungan kerja dengan koefisien regresi sebesar 0,908 artinya semakin tinggi peningkatan lingkungan kerja, makan akan semakin tinggi pula kepuasan kerja karyawan. Hal ini bermakna bahwa terdapat pengaruh yang kuat antara Lingkungan kerja terhadap Kepuasan kerja karyawan.

Pengaruh hubungan interpersonal dan lingkungan kerja terhadap kepuasan kerja karyawan pada ma'had muhammadiyah daarul ulum majenang cilacap.

Koefisien regresi untuk hubungan interpersonal sebesar 0,359 sedangkan koefisien regresi untuk Lingkungan kerja sebesar 0,908 artinya kedua variabel mempunyai pengaruh terhadap Kepuasan kerja. Berdasarkan Uji F menunjukkan adanya keterkaitan antara hubungan interpersonal dan lingkungan kerja secara simultan terhadap kepuasan kerja. Hal tersebut dibuktikan dengan nilai $\mathrm{F}_{\text {hitung }} 194.06>\mathrm{F}_{\text {tabel }} 3,19$.

\section{KESIMPULAN DAN SARAN}

\section{Kesimpulan}

Hasil penelitian dan pembahasan diatas dapat menghasilkan beberapa kesimpulan sebagai berikut:
1. Hubungan interpersonal Ma'had Muhammadiyah Daarul Ulum Majenang Cilacap berdasarkan tanggapan responden termasuk kategori sangat baik.

2. Lingkungan kerja Ma'had Muhammadiyah Daarul Ulum Majenang Cilacap berdasarkan tanggapan responden termasuk kategori sangat baik.

3. Kepuasan kerja karyawan Ma'had Muhammadiyah Daarul Ulum Majenang Cilacap berdasarkan tanggapan responden termasuk kategori sangat baik.

4. Hasil Uji $\mathrm{T}$ diperoleh nilai thitung $3.147>$ tabel 1,299 , maka terdapat pengaruh yang kuat antara hubungan interpersonal terhadap kepuasan kerja karyawan.

5. Hasil Uji $\mathrm{T}$ diperoleh nilai thitung $10.390>$ tabel 1,299 , maka terdapat pengaruh yang kuat antara lingkungan kerja terhadap kepuasan kerja karyawan.

6. Berdasarkan Uji $F$ diperoleh nilai $F_{\text {hitung }} 194.06>F_{\text {tabel }} 3,19$, sehingga dapat disimpulkan bahwa hubungan interpersonal dan lingkungan kerja secara bersamaaan memiliki pengaruh terhadap kepuasan kerja. Degan probabilitas (sig $0,000<$ 0.05), maka dapat disimpulkan bahawa model persamaan tersebut memiliki pengaruh. 
Saran

Berdasarkan poin kesimpulan
diatas, beberapa saran dapat
dipergunakan oleh pihak terkait
sbagaimana berikut:

1. Ma'had Muhammadiyah Daarul Ulum dalam upaya mempertahankan dan mengembangkan hubungan interpersonal sebaiknya mampu membangun komunikasi antara karyawan dengan atasan maupun sesama karyawan dengan karyawan secara objektif dan islami, yang diwujudkan dengan memberikan otoritas dan kepercayaan kepada karyawan sehinga akan lebih bertanggungjawab dalam hal pekerjaan.

2. Pimpinan Ma'had Muhammadiyah Daarul Ulum diharapkan dapat meningkatkan layanan lingkungan kerja agar para karyawan mampu melaksanakan pekerjaan dengan rasa senang dan nyaman, sehingga mampu mencapai target yang telah ditetapkan. Salah satu cara adalah dengan memperbaiki tata letak ruang dan penerangan ditempat kerja.

3. Hubungan interpersonal di Ma'had Muhammadiyah Daarul Ulum Majenang Cilacap mampu memberikan pengaruh yang kuat terhadap kepuasan kerja karyawan. Sehingga diharapkan dapat mengoptimalkan hubungan interpersonal, upaya yang dapat

ditempuh misalnya dengan

mengadakan kegiatan yang

mendorong kerjasama tim, gathering

keluarga, untuk memperlancar

komunikasi dan hubungan secara personal antar karyawan.

4. Lingkungan kerja di Ma'had Muhammadiyah Daarul Ulum Majenang Cilacap mampu memberikan pengaruh yang signifikan terhadap kepuasan kerja karyawan. Sehingga diharapkan dapat memaksimalkan dan mengkondisikan Lingkungan kerja, upaya yang dapat ditempuh misalnya dengan perawatan infratruktur yang berkelanjutan, penggantian intventris yang sudah tidak baik, diharapkan dapat memperlancar aktivitas karyawan.

5. Bagi Peneliti Selanjutnya, Penelitian ini memiliki keterbatasan dari segi keluasan variabel penelitian maupun dari segi objek penelitian. Hal ini terlihat dari analisa regresi bahwa nilai konstanta sebesar 2,9 lebih besar dari nilai rata ratanya sehingga menunjukan masih ada variabel varibel lain yang perlu diteliti. Untuk penelitian selanjutnya, variabel yang digunakan bisa menggunakan variabel lain yang lebih lengkap dan luas cakupannya, misalnya menambah variabel komitmen 
organisasi, gaya kepemimpinan, motivasi dan faktor lainnya atau melakukan penelitian pada beberapa objek yang berbeda agar dapat memberikan kontribusi yang besar bagi penguatan teori hubungan interpersonal, lingkungan kerja dan kepuasan kerja.

\section{DAFTAR PUSTAKA}

Mangkunegara, Anwar Prabu. 2005. Evaluasi Kinerja Sumber Daya Manusia. Bandung: Reflika Aditama.
Rahmat, Jalaludin. 2007. Psikologi Komunikasi. Bandung: PT. Remaja Rosdakarya.

Robbins, Stephen P. dan Timothi A. Judge. 2007. Perilaku Organisasi. Ed.12. Jakarta: Salemba Empat.

Siagian, S. P. 2008. Manajemen Sumber Daya Manusia. Jakarta. Bumi Aksara.

Suharsimi, Arikunto. 2006. Prosedur Penelitian. Jakarta: PT. Rineka Cipta.

Wisnuwardhani, Dian dan Mashoedi, Sri Fatmawati. 2012. Hubungan interpersonal. Jakarta: Salemba Humanika 